\title{
TIPS, TRICKS AND TECHNIQUES IN PRACTICING OR - A DIFFERENT TWIST!
}

\author{
H W ITTMANN \\ CSIR Information and Communications Technology \\ P O Box 395, Pretoria, 0001, South Africa
}

\begin{abstract}
This paper is a personal account of marketing and selling Operations Research (OR) in South Africa. The author reflects on this activity that has occupied him over the past ten to fifteen years.
\end{abstract}

The traditional marketing mix is possibly not ideal for selling a consulting service such as OR. The author shows how he used ingredients such as able people, physical evidence and process in selling the services of the group he represented. The main elements of being successful are: one or more success stories, credibility, a network of people (potential clients), quality staff, a sense of urgency within the group and a recognition that the client is always king.

\section{INTRODUCTION}

This paper is a personal account of marketing and selling Operations Research. It is not a highly scientific or technical paper; rather, it is a personal reflection of taking OR into the market, an activity that has occupied me over the past ten to fifteen years.

The paper originated some two years ago when the Pretoria Chapter of the Operations Research Society of South Africa (ORSSA) held a chapter meeting during which a number of people gave short presentations and personal experiences around "tips, tricks and techniques" used in practicing OR. The request was for speakers to:

- $\quad$ Share a not-so-well-known technique they have found useful;

- Give a tip, or tips, on how to do something faster or better on a project; and

- $\quad$ Share their tricks or shortcuts! 
This led to a most interesting sharing of ideas and various experiences by a number of different OR people. My own presentation was fairly short, but had a different perspective to what had been perceived and expected by the audience. These ideas may be of interest to others too.

\section{APPROACH - PERSONAL REFLECTION}

When approached to give the above-mentioned short presentation, I felt obliged to accept the invitation after some arm-twisting and manipulation. I agreed to participate without giving any real thought to what I would say. By in effect "forcing" me to speak, the lady who had issued the invitation knew I would also attend the chapter meeting!

Sitting down and looking at what was required from the speakers a day or so before the date of the meeting, my immediate reaction was:

- $\quad$ Why me? I don’t practice OR anymore!;

- What tips?;

- What tricks?;

- What techniques?; and

- $\quad$ Why should I share my secrets with people?

This reaction was due to the fact that for a number of years my main responsibility had been to market and sell Operations Research. Business development, getting new projects, talking to new potential clients, convincing people we can solve their problems, etc. has been my daily bread and butter during this period. I therefore had no tips, tricks and techniques in practicing OR that I could offer......... on the other hand, maybe I did, especially since we, as Operations Researchers, had to go out into the market place much more often than was previously the case to identify problems that we could solve and projects we could do! For those who are similarly dependent on contract work it might be useful to know how others do things.

Given our very competitive environment my next thought was: "Why should I share my secrets with others?" These are the things I find useful in marketing our services: "Why should I share this knowledge?" Others might use my ideas to improve their marketing abilities, become better than us and gain some (of our) market share in the process. After 
thinking this over, it dawned on me that it was not all that simple, and I felt an urge to share some of my knowledge with others as it would not only be beneficial to them, but possibly even more so to me. I would focus on these issues much more, learn in the process and I could get feedback or inputs that I might find very useful

\section{MARKETING OR SELLING A CONSULTING SERVICE}

Selling a consulting service, especially something as complex as OR, is not easy. Kaye (1998), in discussing the technical consulting business, states his three fundamental truths of marketing. The second one is of relevance here, namely: "Getting the work is more difficult than doing the work"! I cannot but agree with this!

When anyone has to go out to market or sell a service or product, the first thing usually is to find out what the specialists say. In this regard any marketing handbook will tell you that you need to formulate a marketing mix consisting of the four P's (Kotler (1980) and Kotler (1999)):

$$
\begin{array}{ll}
\text { - } & \text { product; } \\
\text { - } & \text { price; } \\
\text { - } & \text { place; and } \\
\text { - } & \text { promotion. }
\end{array}
$$

From the buyers' point of view these can be described as the four C's:

$$
\begin{array}{ll}
\text { - } & \text { customer value; } \\
\text { - } & \text { cost to the customer; } \\
\text { - } & \text { convenience; and } \\
\text { - } & \text { communication. }
\end{array}
$$

The product or customer value is represented by the service, the brand name, returns, etc. The price or cost to the customer is what the customer pays for the service. The place or convenience is defined as the location, channel, etc. Lastly promotion or communication is the way in which the service is promoted via the sales force, through, for example, direct marketing. In selling a consulting service all four of these are very difficult to define. This realization lead to the following three elements being added (Bitner and Booms, 1981): 
- $\quad$ people (the kind of people one has, their selection, training, etc);

- $\quad$ physical evidence (some way of showing what the service will entail); and

- $\quad$ process (how the service will be offered, routines and systems that will be used).

Operations Research as a concept or service, is difficult to package using the marketing mix of the four P's. In my efforts to market OR I have used these last three elements with much more success than the first four. I will elaborate and expand on them in the next three sections.

It is, however, useful to comment on one or two aspects of the traditional marketing mix. The brand name, CSIR, which is part of the product element, is the name of the organization that I represent and the name means a lot in South Africa. The CSIR is well known as the premier scientific research organization of the country. Almost everyone in the country knows this organization and the name opens doors for anyone trying to sell a consulting service. The CSIR also has a long history and people know that the organization will still be around in future. Clients realize that they can therefore always come back if they need changes, extensions, etc. to whatever was developed for them. These two aspects of the brand name definitely assist in getting work.

\section{PEOPLE}

The first of the three marketing elements added by Bitner and Booms (1981) to the Four Ps was "people". This was described as "the kind of people one has, their selection, training, etc". I will now attempt to apply this to OR.

In any kind of business, you can only be as good as the people you have: they are the biggest assets of any organization. It is essential for a sales or business development person to be able to rely on quality people of high technical ability. If you know that what you are selling will be delivered and backed up by such professional people who do work of high quality, it makes marketing so much easier. The worst thing that can happen to any marketing or sales person is when the workers on the "factory floor" do not perform, or let him/her down. It is the surest way of losing credibility and future work. The work has to be done to the satisfaction of the client. Any client should have confidence in the ability of the "sales person" to ensure quality work by the team doing the work. 
The organisation I represent focuses on complex and difficult problems. We try to find those problems with probably some risk involved in solving them. It is important that able and capable people get involved in solving such problems.

The name, or brand, of the company is also very important. In South Africa almost everyone knows the CSIR and this is a tremendous door-opener. The challenge is to ensure that you and your team can do justice to this perception! The name CSIR implies top scientific people, highly trained and skilled, who can address complex problems.

From a more psychological point of view it is an added motivator if your colleagues know that you, as a business developer, value them in terms of their capabilities, commitment, sense of urgency and client orientation. From their side they will go out of their way to ensure that they not only satisfy the client, but also the business developer!

\section{PRACTICAL EVIDENCE}

The second of the three marketing elements added by Bitner and Booms (1981) to the Four P's was “physical (or practical) evidence". In this section it will be applied to OR marketing.

All of us know that it is very difficult to define Operations Research: Most OR people have experienced that it is not easy to explain to others in simple terms what they do. I find that when someone asks me what I do, I instinctively cannot resist saying that I'm an Operations Researcher. When my children are around they immediately start laughing because they know dad now has to go through a very long explanation of what this thing called OR is. Usually the best way of getting the point across is through success stories or case studies. The same is true, I found, in marketing OR. Success stories are critical!

Soon after we started the operation I am managing we were lucky to get such a success story - which is one that I can still use. ENGEN, the petroleum company in South Africa, contracted us to develop a distribution model for them. The contract was to optimize the distribution of their five major products, namely diesel, kerosene and the three grades of petrol 87, 93 and 97 from the refinery to their depots, and from the depots to the clients. Three modes of transport were available, namely road, rail and pipeline. The model had to be implemented as a decision support system. We, as a relatively unknown group, won the 
contract ahead of a consulting firm from the UK and a local South African management consulting firm.

I believe we did a thorough, quality job in solving this problem for ENGEN. They were more than satisfied with our work. Within ENGEN our direct client was the Manager of Operations. We had a great champion in this person and I used him, almost misused him, as a reference with very good results.

You need to build up a whole range of references: people, organizations, clients, etc. you have worked for and whom you can use as reference points. Being human we have made some mistakes and possibly have a few not so good or even bad references. I even use those! When potential clients ask for references I give them some references and up front indicate that one or two may not be too positive about us. The fact that one is open and honest about this also builds credibility.

In the process of establishing oneself with a new client organization, it is crucial to build up a credible track record as soon as possible. The first project must be done within budget, on time and on brief. The clients have to feel that they are getting real value for money. A satisfied client means so much since it almost guarantees that the client will in future get back to you with other problems. When success stories spread within an organization they become your marketing tools and are the best way of securing follow-up work or repeat business.

Furthermore, one should not be shy to use your network of friends and people you know in the market place. Word of mouth, a word or two by a previously satisfied client can open many doors! Use your networks and build them continuously.

Another very important aspect is to relate a new problem or project to something that has been solved previously by your group. It establishes confidence and credibility. If you can explain to a hesitant or skeptical potential client that you have successfully solved similar problems previously, it makes a huge difference in getting the client to give you the go ahead with a new project.

\section{PROCESS}

The third of the three marketing elements added by Bitner and Booms (1981) to the Four Ps 
was process, earlier defined as "how the service will be offered and routines and systems that will be used". In this section this will be dealt with in terms of OR.

Clients need to feel comfortable that one is able to solve their complex problems. The best way to establish such confidence is through a formal process that needs to be conveyed to a client so that there are no surprises along the way. This formal process can broadly be outlined as follows:

(i) Understand the problem. Before we can do anything we need to get a good understanding of the problem. This is achieved through meeting with those directly involved with the problem area, by asking questions or, if at all possible, by shadowing the person(s) presently closest to the problem area. You may even suggest doing the job for a day or two. In the process you will get to grips with the situation but even more important, you will have gained credibility with both the manager and the people who will have to accept and implement your new proposal. In this process you sometimes have no other alternative but to ask very stupid questions! The aim being to get to the core of the problem. If one wants to develop a model of a problem, you must understand how everything fits together and how everything works. Within a session of one or two hours one can possibly achieve this. You may want to get back at a later stage to confirm your understanding.

(ii) Submit a formal proposal. The proposal outlines in broad terms your understanding of the problem. It describes how you intend solving the problem, it outlines the steps you will follow to achieve this, the deliverables, time scales and finances.

(iii) Indicate how the project will be executed. This is an important step. The traditional steps for developing a model have to be outlined in detail.

(iv) Interact with the client. Close contact with the client is essential. We usually insist in dealing with a contact person or project leader on the client side from the start of the process. Implementation starts at the beginning of the project and therefore the absolute insistence on having a dedicated person from the client interacting with us and involved in the project on a continuous basis.

(v) Highlight data issues up front. Most clients indicate that: "Data is not a problem"! 
They also say all the data needed is immediately available. Usually that is not the case as the data is usually not in the required format or presents other problems. rm we need it Data is usually the biggest problem on a project; it slows down the process and could cause projects to be badly delayed.

(vi) Discuss post-project issues. The client should know what happens after completion of the system. For example who will handle any bugs that may still exist in the software or what about maintenance in the medium to longer term.

\section{MARKETING, SELLING AND BUSINESS DEVELOPMENT OF OR}

In this section a whole variety of different issues are discussed. Each one is an important aspect that anyone in a business development role should take note of and address consciously in any "sales" situation.

Our experience has been that it is much easier for a technical person to become a business developer or a salesperson than the other way round. A non-technical person would find it very difficult to market OR. For successful marketing one should have a very good knowledge, understanding and experience of the technical side of the subject area. It often happens that in a "sales situation" the problem gets discussed in detail within the first few minutes. Some indication of how the problem could be solved, possibly even conceptualizing how the model will be formulated, etc. is needed in an effort to build the confidence in the potential client's mind that the problem can be solved. A technical knowledgeable business developer is imperative in selling OR.

One needs to build credibility in the mind of a client. If you make any promise you must honour it! Not honouring a promise plants a seed of concern in the mind of a client: how can one trust this person if small promises are not kept. Credibility is also earned through being knowledgeable and through the track record built over the years. Success stories contribute towards establishing a track record, but one also needs exposure. The latter is obtained through papers at conferences, articles in journals, etc.

Any business developer must be confident and believe in him/herself and what is being offered to a client. Confidence in the product or service that is being offered is essential, as well as confidence in your own ability to not only interact with a client, but in really 
understanding and dealing with the complex problem situations that you might be confronted with. This leads to another characteristic namely being able to "think on your feet" while interacting with clients in a difficult "sales situation". In many situations one has a preconceived plan and idea about handling the situation, but many, many times things work out totally differently and one needs to be able to handle such a situation in a confident way. For example, it happens often that you think you are going to sell $\mathrm{x}$ to a customer, but this is not what the customer wants to buy, so you have to sell y!

It has on many occasions been my experience that during an interaction with a client, the discussion and the whole meeting revolve around exchanging niceties and sharing stories. Remember, in any business development interaction the sole and ultimate purpose is to do business. It must be clear to the potential client that this is the reason for the interaction. It ensures that there is a mutual understanding and some focus on the actual issue.

At the end of the meeting it is essential to have an agreed action plan: what is the next step, who has what responsibilities and obligations, and when will there be a next meeting. Never leave without an action plan! An action plan may even be of the nature that there is currently nothing of interest and the two parties agree to meet again in six months.

A meeting with the aim of getting a project is not just a pleasant get-together. It sometimes is necessary to push to get a project. One should use all your efforts, all your charm and diplomacy to get the client to move closer to formulating a project and agreeing on getting a proposal. Therefore be aggressive in a polite way!

During an interaction many things are said. An off-the-cuff remark may be a further opportunity for another project. Listen attentively and carefully, and always be on the lookout for new opportunities. The ability to listen well to what people are telling you is an essential element of salesmanship.

In any interaction with a potential or current client one should always have quality as the prime objective. Anything presented to, done for or given to the client should be of high quality. For example a proposal should have quality written all over it. There should not be any mistakes, the argument being that if a proposal is full of mistakes, how can one trust the technical ability or capability of the provider of the service! Quality should be a "mind set", a 
way of doing things and every employee should live and breathe quality. Quality should be entrenched in the organization and the emphasis should be on continuous improvement of the standard of anything we do! The best way of selling oneself or an organization is through delivering quality work. You build up credibility in the process and a track record of quality work with the result that follow-up work readily comes your way.

No business developer should ever become arrogant or overly confident. Remember one should remain humble because the client is king - always!

\section{CONCLUSION}

In marketing, business development and selling each individual has his or her own style. Some people feel comfortable doing it one way while others do it in a different way. In the end it is the drive, the enthusiasm, the passion and the persistence of the business developer that will ensure a contract or not. This drive, enthusiasm, passion and persistence are crucial and are possibly the most important aspects of business development. The energy you are prepared to put into this will determine success or failure. There is a song that captures it all (with a crucial adaptation) "I don't like OR - I love it!!"

\section{REFERENCES}

[1] M.J. BITNER and B.H. BOOMS, "Marketing Strategies and Organizational Structures for service firms," in Donnelly, J.H. and W.M. George (ed) Marketing of services.American Marketing Association, Chicago, 244 (1981).

[2] H. KAYE, Inside the Technical Consulting Business, $3^{\text {rd }}$ Edition, John Wiley \& Son,New York, 366 (1998).

[3] P. KOTLER, Marketing Management - Analysis, Planning and Control, $4^{\text {th }}$ Edition, Prentice/Hall International, Inc., London, 722 (1980).

[4] P. KOTLER, Kotler on Marketing - How to create, win and dominate markets, The FreePress, New York, 257 (1999). 